Conspicuous Confusion? A Critique of Veblen's Theory of Conspicuous Consumption Author(s): Colin Campbell

Source: Sociological Theory, Vol. 13, No. 1 (Mar., 1995), pp. 37-47

Published by: American Sociological Association

Stable URL: http://www.jstor.org/stable/202004

Accessed: 09/10/2011 02:01

Your use of the JSTOR archive indicates your acceptance of the Terms \& Conditions of Use, available at http://www.jstor.org/page/info/about/policies/terms.jsp

JSTOR is a not-for-profit service that helps scholars, researchers, and students discover, use, and build upon a wide range of content in a trusted digital archive. We use information technology and tools to increase productivity and facilitate new forms of scholarship. For more information about JSTOR, please contact support@jstor.org. 


\title{
Conspicuous Confusion? A Critique of Veblen's Theory of Conspicuous Consumption*
}

\author{
COLIN CAMPBELL \\ University of York
}

\begin{abstract}
Veblen's concept of conspicuous consumption, although widely known and commonly invoked, has rarely been examined critically; the associated "theory" has never been tested. It is suggested that the reason for this lies in the difficulty of determining the criterion that defines the phenomenon, a difficulty that derives from Veblen's failure to integrate two contrasting conceptual formulations. These are, first, an interpretive or subjective version that conceives of conspicuous consumption as action marked by the presence of certain intentions, purposes, or motives, and second, a functionalist formulation in which conspicuous consumption is viewed as a form of behavior characterized by particular end results or outcomes. Consideration of each of these strands reveals major difficulties that prevent the construction of an operational definition of conspicuous consumption and hence the extraction of a workable theory from Veblen's discussion.
\end{abstract}

Although it would be untrue to say that Thorstein Veblen's work has been entirely neglected by sociologists, few of his concepts or theories figure in ongoing debates or are employed in research. In part this can be attributed to his extensive use of an evolutionary framework, combined with an instinctivist psychology, both of which appear very old-fashioned in the context of contemporary sociological thought. The principal reason, however, is probably that his reputation rests largely on his role as a social critic and commentator rather than as social theorist. Thus C. Wright Mills (1957), probably the most obvious inheritor of Veblen's mantle, described him as "the best critic of America that America has produced" rather than as the best sociologist; other figures who have followed in Veblen's footsteps, such as Max Lerner (1957) and David Riesman (Riesman, Glazer, and Denny 1950), also would seem to be more deeply indebted to his ironic and radical style of social criticism than to his sociological theorizing.

Whatever the reason might be, however, it is likely that few contemporary sociologists would be able to identify Veblen's significant or distinctive contribution to sociological theory; the one obvious exception is his concept of conspicuous consumption. Yet this term, which Veblen invented, is not familiar only to most sociologists; it has become part of everyday language. Strangely, despite this, the associated theory is little discussed in sociology; as a consequence, Veblen's influence as a theorist has been more pervasive in economics, where the term Veblen effect has an established place in the theoretical vocabulary. This continuing neglect is difficult to understand, given the prominence accorded to consumption and consumer behavior in contemporary debates about the "postmodern society" and the "postmodern condition" (see, for example, Baudrillard 1975, 1988; Feath-

\footnotetext{
* This article is based on a paper originally presented to the Second International Conference on Consumption, held in Helsinki in September 1989. Please address correspondence to the author at the University of York, Heslington, York Y01 5DD, England.
} 
erstone 1991; Jameson 1987), as well as the widespread use made of Veblen's theory by historians. ${ }^{1}$

Although Veblen's term is often used in little more than a vague descriptive sense to refer to any nonutilitarian forms of consumption, or merely to that which is judged extravagant, luxurious, or wasteful, some writers seem to regard Veblen as offering a theory that can be used to account for distinctive patterns of consumer behavior. The problem with this view is that such usage suggests that a coherent set of widely accepted propositions exists; that there is, in fact, an agreed theory of conspicuous consumption. Yet despite the extraordinarily dominant position of Veblen's theory in both popular and academic consciousness, one must admit that the theory itself has not been the object of much serious discussion and debate, let alone the subject of empirical inquiry. Indeed, it appears that only one extended effort has been made to evaluate the theory as a whole (Mason 1981); significantly, this is the work of an economist, not a sociologist. Meanwhile, nobody has made a systematic attempt to verify the theory itself. Thus, although some aspects of Veblen's general theory have been considered from time to time (for examples, see Adorno 1967; Davis 1944), the theory of conspicuous consumption has yet to be examined critically. Consequently the purpose of this paper is less to focus on a neglected theorist than on a neglected theory, and to focus in particular on two crucial issues. First, what exactly is Veblen's theory, and is it clear and unambiguous enough in its conceptualization to permit agreement on its central propositions? Second, and arising from the first question, can the theory be formulated in such a way that it can be tested?

The widespread popular use of the term conspicuous consumption, coupled with the lack of scholarly assessment, has combined to create some confusion over the precise nature of Veblen's concept. Thus, although one can find definitions of the term in both popular and specialized social science dictionaries and encyclopedias (Bullock and Stallybrass 1977; Gould and Kolb 1964), these often refer to commonsense understandings of this phenomenon rather than to Veblen's own usage. Therefore, it seems wise to proceed by attempting to identify the theory that is actually contained in The Theory of the Leisure Class. Unfortunately this is more easily said than done, because Veblen's ironic and satirical tone, coupled with his deliberate rejection of a conventional scholarly style, compels the reader to work hard to determine precisely what he had in mind. The more serious problems, however, tend to arise from the ambiguities that are inherent in Veblen's functionalist approach.

\section{CONSPICUOUS CONSUMPTION AS DISTINGUISHED BY AN INTENTION, MOTIVE, OR INSTINCT}

A common way of describing conspicuous consumption is to present it as a pattern of conduct that is intended to realize the goal of maintaining or enhancing an individual's social position (see, for example, the entries in Bullock and Stallybrass 1977 and in Gould and Kolb 1964). This view apparently is strengthened by a casual reading of The Theory of the Leisure Class. Such a reading is likely to give the reader the impression that the theory of conspicuous consumption concerns a particular form of rational purposive conduct, one in which status considerations predominate, because Veblen generally implies that individuals consciously seek to "excel in pecuniary standing" and so "gain the esteem and

1 Thus Lawrence Stone (1965) employed Veblen's concept of conspicuous consumption in his study of the English aristocracy between 1558 and 1641, as does Peter Burke (1987) in his study of early modern Italy. Meanwhile there has been an extensive debate over the role of Veblenesque theories of social emulation in understanding the "consumer revolution" in eighteenth-century England (see Campbell 1987; McKendrick, Brewer, and Plumb 1982; Perkin 1968; Weatherill 1988). 
envy of (their) fellow-men" ([1925]1970:32). Certainly he refers continually to individuals as either struggling to "outdo one another" ([1925]1970:88), "desiring to excel everyone in the accumulation of goods" ([1925]1970:32), or engaging in "a restless straining to place a wider and ever-widening pecuniary interval between (themselves) and (the) average standard" ([1925]1970:31). Thus the impression is that in this Hobbesian version of social existence, all actors are well aware of the nature of the struggle in which they are engaged and would have no difficulty in recognizing Veblen's account as a true description of their conduct. Consequently the conclusion would appear to be that conspicuous consumption is an activity distinguished by individuals' deliberate, conscious endeavors to achieve a particular end. Although this goal is described variously in the quotations given above, the common theme seems to be that individuals seek 1) to excel in their manifestation of pecuniary ability or pecuniary strength in order to 2) impress others and thereby 3) gain their esteem or envy. From this it would appear reasonable to conclude that conspicuous consumption is a category of intentional actions in which the goal is to bring about an improvement in others' opinions of oneself.

A closer reading of Veblen, however, suggests a somewhat different understanding of the phenomenon of conspicuous consumption, one in which it could be said that the motives underlying conduct are emphasized more strongly than formulated goals or intentions. It is clear, for example, that Veblen places special emphasis on what he calls "the emulative motive," asserting repeatedly that "the motive that lies at the root of ownership is emulation" ([1925]1970:25). Yet it is not entirely clear what Veblen means by calling emulation a "motive," for the verb to emulate merely suggests a form of action that is guided by the intention of equaling or surpassing someone; it does not necessarily imply anything about the motive for such conduct.

To complicate matters further, Veblen repeatedly equates emulation with the making of invidious comparisons. Apparently he believes that the one must always imply the other, even though the making of comparisons, like emulation, is not a motive in the normal sense of the word. An accompanying emotion, however, such as envy, might well be such a motive. ${ }^{2}$ Yet Veblen seems to have believed that making such comparisons inevitably lead to emulation: he writes, "Emulation [is] the stimulus of an invidious comparison which prompts us to outdo those with whom we are in a habit of classing ourselves" ([1925]1970:103). From this perspective, conspicuous consumption is that conduct which arises out of the motive of emulation, which Veblen judges to be "of ancient growth and ... a pervading trait of human nature." Indeed, he believes that after the "instinct of self-preservation," it is "probably the strongest and most alert and persistent of the economic motives proper" ([1925]1970:110). As suggested by the above quote, Veblen seems to have viewed emulation more as an "instinct" than as a motive proper. Such a position might help explain how conspicuous consumption could be viewed as intentional (in the sense of being purposeful), although not voluntary - that is to say, resembling instincts in animals and birds in being a practice that is preprogrammed and common to a species.

Naturally, if conspicuous consumption arose from an instinct in this sense, individuals might not be aware of the extent to which their conduct took this form. Consequently they could easily be deceived into thinking they were acting for other reasons, when in fact the

2 To what aspect of reality (if any) the term motive might apply is a matter of dispute among sociologists. Although Weber (1964) used the word to refer both to the reasons for acting and to emotive forces that might impel individuals to act. other writers, following the line of argument initiated by C. Wright Mills (1940), have attempted to restrict its meaning to "words" (Scott and Lyman 1970; Semin and Manstead 1983). The position taken here is that this "vocabulary of motives" tradition is unrelated to understanding how individuals' conduct is actually initiated and carried through to completion (Campbell 1991). Hence, for the purpose of this discussion, a motive is assumed to be a subjectively meaningful experience, composed of thoughts and emotions, which prompts an individual to act. 
"law of conspicuous waste" was determining their actions. Indeed, this also seems to have been Veblen's position: he observes that "most . . . wasteful consumption" does not stem from "a conscious effort to excel in the expensiveness of . . . visible consumption, so much as it is a desire to live up to a conventional standard of decency in the amount and grade of goods consumed" ([1925]1970:102). Thus it is that "the law of conspicuous waste guides consumption ... chiefly at the second remove, by shaping the canons of taste and decency" ([1925]1970:168). Hence, according to Veblen, while people bend their efforts to live up to a given "ideal of decency" and act out a standard of living that they have learned to regard as "right and good" ([1925]1970:84), they are exemplifying, in reality and unknowingly, the law of conspicuous waste. Therefore, according to this version of the theory, a sharp contrast exists between the conscious intentions of consumers, which are directed at realizing that "ideal of consumption" which lies just beyond their reach, and the "motive" (or "instinct") of emulation, which is actually impelling such conduct.

In an alternative interpretation, conspicuous consumption is a form of conduct marked by specific conscious "motives." This cannot really include emulation because emulation, in such a case, would appear to be less a motive than the outcome of a motive. In fact, at least three possible motives for emulative conduct can be discerned in Veblen's discussion. The first of these is the protection or enhancement of esteem. One of Veblen's clearest arguments about the psychological mechanism underlying the activity of conspicuous consumption is as follows: Wealth confers honor; individuals are esteemed in proportion to the wealth they possess, while an individual's self-esteem depends on the esteem accorded by others. It follows that fluctuations in an individual's perceived wealth will lead to changes in self-esteem. Hence, to protect or enhance self-esteem, an individual will find it necessary to display considerable "pecuniary strength." But Veblen also suggests other, rather different motives for such conduct. He refers, for example, to the "satisfaction" that comes from having "widened the pecuniary interval" between oneself and those with whom one is in the habit of classing oneself, and to the "gratification" that comes from "possessing something more than others" ([1925]1970:31). Interestingly, these motives, unlike the motive of esteem mentioned above, do not rely in any way on the reaction of others. Finally, Veblen mentions the "desire . . to gain . . . the envy of one's fellow-men" ([1925]1970:32) as a motive for striving to conspicuously consume. ${ }^{3}$

We now can conclude that no fewer than three different accounts seem to fall under the single overall heading of Veblen's interpretive theory of conspicuous consumption. First is that form in which conscious intentions are crucial; second, that in which unconscious motives (or motive forces such as instincts) are crucial; and third, that in which conscious motives are crucial. The two dimensions of contrast here are 1) motives versus intentions and 2) deliberately purposive versus unknowingly prompted actions.

\section{CONSPICUOUS CONSUMPTION AS DISTINGUISHED BY A CONSEQUENCE, OUTCOME, OR FUNCTION}

Almost as common as those definitions of conspicuous consumption which are expressed in terms of a given goal, intention, or purpose are those which are expressed in terms of a distinctive consequence or function (for a famous instance of such usage, see Merton 1957). According to this formulation, conspicuous consumption is not marked by any special subjective states in individuals, but rather by objective states "in the world." The most obvious way of viewing conspicuous consumption in these terms is as conduct that results

\footnotetext{
3 Veblen notes that there might be motives other than consumption for accumulating wealth. He mentions comfort and security from want, but considers these to be "insignificant" when compared with emulation.
} 
in others' being impressed by the actor's pecuniary strength. As we have had cause to note above, however, Veblen presents more than one account of the critical outcome. Is impressing others really crucial, or is the actual process of "widening the pecuniary interval" and hence "excelling in pecuniary standing" sufficient in itself? Is the object to enhance status or prestige? Finally, is conspicuous consumption conduct that impresses others, or conduct that the conspicuous consumer believes has succeeded in impressing others? To consider these (and other) questions, it will be useful at this point to examine one of the very few examples provided by Veblen.

Although Veblen claimed that there was ample evidence to support his theory (in the form of both academic research and direct personal observation), he presented hardly any extended examples in his book. Nonetheless, his discussion is interspersed with some tantalizing suggestions; one of these can be examined profitably to show how it illuminates his more general and abstract claims. As an example of conspicuous consumption among the laboring classes of America in the late nineteenth century, Veblen cites the practice of dram-drinking, particularly "treating," which was prevalent among handicraftsmen and especially journeymen printers. He comments on the geographical mobility that was such an important feature of the life of these workers; they, as a result, regularly spent much of their lives traveling from town to town. One consequence was that printers constantly were thrown into contact with new groups of acquaintances with whom "the relations established are transient or ephemeral, but whose good opinion is valued none the less for the time being" ([1925]1970:90). This "good opinion" then was sought through the practice of buying drinks or "drams" for one's new workmates, an activity that Veblen suggests is a form of "conspicuous consumption."

Some important points can be noted about this (admittedly rather vague) example. Certainly one can appreciate that an itinerant printer may be tempted to spend freely on drink when first thrust among new workmates, and to indulge extensively in treating. It is also reasonable to claim, as does Veblen, that he may do this out of a spirit of good-fellowship, in addition to a desire to show off. More difficult to accept, however, is the assumption that his drinking companions will necessarily regard his generosity as evidence of his high pecuniary standing or wealth, as the theory of conspicuous consumption requires. Although this outcome is possible, it would seem more likely that they would simply attribute his conduct to a desire to be accorded their "good opinion," and they might well assume that he would be willing to run up a sizable debt in pursuing this goal. Yet no matter what assumptions they might make about the source of the money he spends, it seems more than likely that they will view his conduct as indicating his character rather than his financial circumstances. That is to say, his action in treating his new workmates will be judged as a sign that he is a generous and sociable person, someone who likes a good time and is in every way "a good fellow." Hence, although his conduct indeed may earn him high esteem from his new colleagues, this is not so much because they recognize his high pecuniary standing as because they value such personal qualities.

Veblen, however, not only fails to recognize that esteem might be accorded for such reasons; he also fails to make the crucial distinction between that esteem and deference which is accorded to individuals because of such personal qualities as generosity, bravery, kindness, wisdom, and style, and that which is accorded to them as occupants of prestigious social positions. In view of his basic assumption that the status system of a society is built around differences in wealth, the "pecuniary standing" of individuals is equivalent to their social status. Hence whatever deference or esteem is accorded them as a result arises from their social position, not from their personal characteristics. In the example given above, however, the journeyman printer probably has not affected his general social standing in any way through his practice of treating: although he is now popular with his fellow 
workers, it is unlikely that his position in the eyes of his landlord, his employer, or even his own family has changed in any way whatever.

Yet another, equally important point can be made about the above example, concerning the relationship between the consumer and those whom he or she would wish to impress. Veblen seems to assume that the printer has earned the esteem of his new friends by impressing them with his wealth, when any neutral observer surely would conclude that any such esteem has merely been "bought." A significant difference exists between those situations in which observers are impressed by one's ostentatious expenditure, although they do not benefit from it, and those in which the good opinion of others is linked to the fact that one's wealth has been spent on them. It is clearly not part of Veblen's theory to suggest that wealth enables individuals to purchase honor or esteem. On the contrary, he claims that wealth is intrinsically honorific and hence confers status on its possessor, no matter how it is spent; the only proviso is that it must be expended in an ostentatious and conspicuous manner. The example cited above is thus inappropriate because it describes a situation in which the relationship between consumer and audience is confused with that between the treater and the treated. This confusion, however, is probably not accidental, because practices that are often presented as excellent examples of conspicuous consumption frequently turn out, on examination, to include this additional dimension. This is most obviously true of the potlatch, the American Indian ritual feast that Diggins claims was Veblen's original inspiration for the idea of conspicuous consumption (1978:104). It also applies to the instances of conspicuous consumption suggested by Aryeh Spero (1988). In these examples the conspicuous consumer is also the host of a banquet; he may seek not merely to impress his guests but also to embarrass them with the size of the indebtedness, which custom requires them to repay.

Viewed in this light, impressing through ostentatious display becomes merely one of a set of reasons for engaging in the conduct concerned; these reasons include the normal obligations of hospitality, the desire to be thought generous, and the advantages of incurring indebtedness in others. More pertinently, it becomes impossible in these cases to determine how much of any ensuing esteem accorded the consumer actually derives from the element of conspicuous consumption, as opposed (say) to the degree of generosity displayed or the overall success in performing the role of host. If any convincing examples of conspicuous consumption are to be found, they must relate to situations in which there are no additional complicating relationships between consumer and audience.

To follow up this point, it is worth considering the nature of this audience more closely, and deciding who exactly is likely to be impressed by conspicuous consuming and under what circumstances. In this connection we may note that Veblen's discussion accords a pivotal role to others in two different ways. First, the impulse to engage in conspicuous consumption derives, according to Veblen, from a process in which individuals compare themselves with others (the so-called "invidious comparison" or "emulation"). Second, the success or failure of the act of conspicuous consumption is judged in terms of the reactions of others. Unfortunately, Veblen's comments about these two groups of others (comparators and audience) are rather vague in both respects: it is not at all clear whether he considers them to overlap, or indeed whether either or both are to be considered identical with the conspicuous consumer's own membership group. As for the question of comparison, Veblen refers to an individual seeking to possess as many goods as "others with whom he is accustomed to class himself" ([1925]1970:31), and to people's general tendency to strive to "outdo those with whom they are in the habit of classing themselves" ([1925]1970:103). Thereby he suggests an identity not only between membership and reference group but also between comparators and competitors. In fact, we know from the research on reference group behavior that individuals may compare themselves with several different social 
groups (or categories or role models) for a variety of purposes, and that these groups may or may not coincide with either their membership group or those whom they regard as competitors for social status and prestige (see Merton 1957:281-384). The situation is only a little less confused with respect to audience groups. Often Veblen merely refers to individuals seeking to gain the esteem and envy of their "fellow-men," although the most common impression is that he assumes these to be drawn from the membership group. Yet he is not consistent in this regard, and his discussion leaves the issue confused in two crucial respects.

The first concerns the target audience. Are conspicuous consumers people who reveal their ostentatious consumption to all and sundry, simply displaying pecuniary strength indiscriminately to whoever happens to be present to witness it? Or do they take care to ensure that it is visible to precisely those people whom they wish to impress? The example of the itinerant printer suggests the latter because he presumably had a clear idea of whom he was prepared to treat. Also, Veblen says at one point that conspicuous consumption is normally concentrated on those lines "which are most patent to the observers whose good opinion is being sought" ([1925]1970:112); this observation certainly suggests targeting. At other times, however, Veblen writes about conspicuous consumers as if their concern was to succeed in impressing anyone they might meet, no matter how fleeting the interaction or how unknown the observer. ${ }^{4}$

This point in turn raises the second and related issue concerning the audience group. Does it merely consist of persons known to the individuals concerned, and with whom they habitually interact, or can it be said to embrace anonymous and unknown observers of their conduct?

In fact, Veblen recognizes the significance of this contrast, identifying it with the shift from traditional to modern society. In the latter, he observes, "one's neighbours, mechanically speaking, often are socially not one's neighbours, or even acquaintances" ([1925]1970:87). Hence in comparison with traditional society, which was characterized by greater intimacy and personal knowledge of others, in modern society a larger part of the potential audience for one's consumption consists of anonymous individuals. As Veblen notes, it is not merely a matter of not knowing your neighbors; it is also that "in the modern community there is also a more frequent attendance at large gatherings of people to whom one's everyday life is unknown; in places such as churches, theatres, ballrooms, hotels, parks, shops and the like" ([1925]1970:87). Veblen concludes from these observations that because, in a fleeting or impersonal encounter, all that a stranger can know about one is based on what is visible, one's pecuniary strength must be displayed clearly and unambiguously through one's appearance. In Veblen's graphic phrase, if one is to impress the largely anonymous observers of one's everyday life, "the signature of one's pecuniary strength should be written in characters which he who runs may read" ([1925]1970:87).

The problem with this argument is simply that it seems to beg a rather important question: Why should anyone want to impress this ever-changing and anonymous mass of potential observers?

Veblen's original argument was that the conspicuous consumer sought to impress others with his wealth in order to win their esteem and thus, it was hoped, to maintain or improve his social status. Yet it is hard to see how this argument could apply in instances where one's conduct is scrutinized fleetingly by a number of unknown observers: no matter what impression one might succeed in forming in their minds, it is difficult to know how it could affect one's social status. In the absence of the regular and continued interaction that

\footnotetext{
${ }^{4}$ Mason assumes that the true conspicuous consumer is someone who has a clear target audience in mind, namely "the social group to which the individual aspires or of which he is a member" $(1981: 34)$.
} 
individuals need to get to know one another, any judgment passed on the consumer, whether considered individually or in aggregate, is of little consequence. Therefore why should anyone bother at all to "write the signature of (their) pecuniary strength" in their appearance? Then again, one might well ask how, in any case, the consumer would know either that others had been able to "read" this signature, or indeed that they were suitably impressed.

This latter issue is also quite crucial for Veblen's theory as a whole; yet he does not address it. Throughout the discussion he stresses that conspicuous consumption is conduct directed at others with the specific intention of impressing them and, if possible, arousing their envy. Yet he does not consider how conspicuous consumers know they have succeeded in this aim. In those instances cited above, in which the observers are unknown to the consumer and interaction is effectively nonexistent, it would seem that the individual simply cannot know. Yet it is not clear that the situation is very different with respect to those people whom the actor knows well. How, for example, did the journeyman printer know that he had impressed his fellow workers? How does anyone who buys and displays an expensive item know that the intended audience is indeed impressed? Positive and complimentary remarks cannot always be accepted at face value. Etiquette, custom, and the norms of politeness may all serve to conceal an audience's real thoughts and feelings. Then again, even if the admiration is real, it may not be easy to establish that it derives directly from an assessment of one's wealth, as inferred from the products displayed, rather than from some other source. It would seem that conspicuous consumers face almost insurmountable difficulties in establishing whether they have achieved their aim.

This conclusion is important because it reveals that conspicuous consumption is a form of conduct with two different sets of consequences: those changes, if any, which have occurred in the attitudes and opinions of others, and those which the aspirant conspicuous consumer imagines have occurred. This second category is crucial because it is likely to determine the consumer's subsequent conduct. If conspicuous consumption is viewed as a continuing pattern of activity, such conduct presumably will be repeated only if it is judged successful. But will a pattern of conduct persist if the individuals concerned are unable to judge whether they have succeeded? One would think not, in which case there is an unresolved problem concerning the mechanism that perpetuates individuals' efforts to conspicuously consume.

All these problems arise directly from Veblen's functionalism and constitute some of the better-known deficiencies of this method. In 1968 Arthur K. Davis was able to describe Veblen's method as "strikingly modern," stating, "He practised, without so naming it, the analysis of latent or unintended functions of social phenomena" (p. 306). Indeed, Robert Merton, in his own famous account of latent and manifest functions, cites Veblen's theory of conspicuous consumption as a classic example of functional analysis (1957:65). Merton's distinction, however, is not so easy to apply in practice as he suggests in his discussion. As several commentators have observed (Giddens 1976; Helm 1971; Isajiw 1968; Levy 1952; Spiro 1961; Sztompka 1974), intention and recognition can vary independently of each other, while the logic underlying the distinction is also questionable (see Campbell 1982). Individuals not only may recognize that actions have consequences which they never intended; they may even anticipate those consequences. Similarly, a person who spends lavishly may recognize that others may be impressed by his or her "pecuniary strength"; yet it does not follow that this was the intention. Conversely, a person who spends lavishly with the express intention of impressing others may fail to do so; "impressing others" is an outcome that is more likely to occur, as Elster observes (1983:66-70), as a byproduct of conduct undertaken for other reasons.

These issues are central to identifying a clear set of propositions that might constitute a 
satisfactory theory of conspicuous consumption. For if, as Merton suggests, this form of behavior represents a "latent function" in the sense of an unintended and unrecognized outcome of action undertaken for other reasons, then it becomes necessary to specify not only why the conduct was undertaken in the first place, but also how the actors' conscious intentions are related to this particular outcome. It is critically important to specify (but difficult to envisage) the feedback processes that lead the actor to repeat the act. Veblen's solution to this particular problem, which was to invoke an emulative "instinct," is unlikely to convince many contemporary sociologists. If conspicuous consumption is defined, however, as a form of conduct that is undertaken consciously and intentionally, with the explicit aim of impressing others with one's wealth, then it is still necessary, if there is to be an adequate theory of conspicuous consumption, to specify clearly who the target audience is considered to be, what motivates the individual to undertake this action, how he or she knows whether the action has been successful, and exactly in what way success or failure leads to repeated acts of the same kind. Veblen, as we have seen, does not address these questions.

\section{CONCLUSION}

The purpose of this paper was to focus on a neglected theory rather than on a neglected theorist, and to do so by examining how conspicuous consumption is defined. This required a close reading of the text of The Theory of the Leisure Class and the disentangling of different strands of argument. What now can one conclude as a result of considering these strands? Either singly or together, do they constitute a sufficient basis for an adequate definition of the phenomenon? One which could be employed, for example, as the basis of a program of research to test the nature and extent of conspicuous consumption in contemporary society? The answer would hardly seem to be an unqualified "yes," because serious difficulties were noted.

As for viewing conspicuous consumption as behavior that leads to specific consequences (or fulfills given functions), one naturally encounters all the familiar problems associated with the functionalist method. Thus it naturally excludes conduct that fails in its goal, although marked by such intentions, while including conduct that was not prompted by any such intention, although marked by a successful outcome. Also, it fails to allow for other means of achieving the same goal (that is, functional alternatives). Hence it would be unreasonable to assume that just because an individual's conduct succeeds in impressing others, thereby enhancing his or her status, such conduct could be attributed to that person's consumption activity (let alone the manifestation of "pecuniary strength") unless other alternatives (such as the manifestation of personal qualities) have been considered.

By comparison, that interpretive approach which treats conspicuous consumption as the manifestation of specific subjective states within the individual appears, at first sight, to be relatively persuasive. Yet difficulties also were noted here. Most important, it is unclear whether the crucial defining criterion is an intention (such as "outdoing" others or "excelling in pecuniary standing") or a motive (such as "envy" or the "gratification" of knowing that one has more than others). Then, in addition, it is uncertain whether the operative motives and intentions should be viewed as conscious, subconscious, "instinctive," or merely embodied in habitual practices. Finally, both subjective and functionalist formulations involve highly problematic assumptions about both the nature of the "audience" for this activity and the precise feedback processes through which achieving the desired effect on this audience causes the actor to repeat the act of conspicuous consumption.

These problems suggest that Veblen's most famous concept is insufficiently clear in its formulation to permit any general agreement on its definition. In such a case, there would 
seem to be little possibility that sociologists might agree on a set of propositions constituting a "theory" of conspicuous consumption. For example, if individuals are considered to be unaware of their own motives and intentions, how would one know what data to collect in order to determine that their conduct should count as conspicuous consumption? On the other hand, if this form of conduct is deemed to be the product of conscious motives or intentions, which of the several possibilities discussed warrant inclusion under this designation? Perhaps if this latter difficulty could be resolved, and if a clear conception of the subjective nature of the act of conspicuous consumption could be determined, one might be able, through careful and sensitive interviewing, to establish the context and extent of its occurrence in reality.

One final problem, however, appears to stand in the way of pursuing even this limited research strategy. According to Mason, the conspicuous consumer, "anxious to display wealth and gain in prestige, will rarely if ever explicitly admit to any such intentions" (1981:42). Thus even if one concluded that conspicuous consumption could be defined by the presence of specific conscious intentions, the researcher might well find that no informants were willing to admit that this definition applied to them.

\section{REFERENCES}

Adorno, Theodor W. 1967. Prisms. Letchworth, Herts.: Neville Spearman.

Baudrillard, Jean. 1975. The Mirror of Production. St. Louis: Telos.

. 1988. "Consumer Society." Pp. 29-56 in Jean Baudrillard: Selected Writings, edited by Mark Poster.

Oxford: Polity.

Bullock, Alan and Oliver Stallybrass, eds. 1977. The Fontana Dictionary of Modern Thought. London: Fontana/Collins.

Burke, Peter. 1987. The Historical Anthropology of Early Modern Italy. Cambridge, UK: Cambridge University Press.

Campbell, Colin. 1982. “A Dubious Distinction? An Inquiry into the Value and Use of Merton's Concepts of Manifest and Latent Function.” American Sociological Review 47:29-44.

1987. The Romantic Ethic and the Spirit of Modern Consumerism. Oxford: Blackwell.

1991. "Re-Examining Mills on Motive: A Character Vocabulary Approach." Sociological Analysis 52:89-98.

Davis, Arthur K. 1944. "Veblen on the Decline of the Protestant Ethic." Social Forces 22:282-86.

1968. "Thorstein Veblen." Pp. 303-308 in The International Encyclopedia of the Social Sciences, edited

by David L. Sills. New York: Macmillan.

Diggins, John P. 1978. The Bard of Savagery: Thorstein Veblen and Modern Social Theory. Brighton, UK: Harvester.

Elster, Jon. 1983. Sour Grapes: Studies in the Subversion of Rationality. Cambridge, UK: Cambridge University Press.

Featherstone, Mike. 1991. Consumer Culture and Postmodernism. London: Sage.

Giddens, Anthony. 1976. "Functionalism: Après la lutte." Social Research 43:325-66.

Gould, J. and W.L. Kolb, eds. 1964. A Dictionary of the Social Sciences. London: Tavistock.

Helm, Paul. 1971. "Manifest and Latent Functions." Philosophical Quarterly 21:51-60.

Isajiw, Wsevolod W. 1968. Causation and Functionalism in Sociology. London: Routledge and Kegan Paul.

Jameson, Frederic. 1987. "Postmodernism and Consumer Society." Pp. 5-32 in Postmodern Culture, edited by Hal Foster. London: Pluto.

Lerner, Max. 1957. America as a Civilization. New York: Simon and Schuster.

Levy, Marion J. 1952. The Structure of Society. Princeton: Princeton University Press.

Mason, Roger S. 1981. Conspicuous Consumption: A Study of Exceptional Consumer Behaviour. Farnborough, Hants: Gower.

McKendrick, N., J. Brewer, and J.H. Plumb. 1982. The Birth of a Consumer Society. London: Europa.

Merton, Robert K. 1957. Social Theory and Social Structure, revised and enlarged ed. New York: Free Press.

Mills, C. Wright. 1940. "Situated Actions and Vocabularies of Motive." American Sociological Review 5:904-13. . 1957. "Introduction." Pp. v-xxi in The Theory of the Leisure Class: An Economic Study of Institutions,

by Thorstein Veblen. London: Unwin. 


\section{A CRITIQUE OF VEBLEN'S THEORY OF CONSPICUOUS CONSUMPTION}

Perkin, Harold. 1968. The Origins of Modern English Society. London: Routledge and Kegan Paul.

Riesman, David, Nathan Glazer, and Reuel Denny. 1950. The Lonely Crowd: A Study of the Changing American Character. New Haven: Yale University Press.

Scott, Marvin B. and Stanford M. Lyman. 1970. "Accounts." American Sociological Review 33:46-62.

Semin, G.R. and A.S.R. Manstead. 1983. The Accountability of Conduct: A Social Psychological Analysis. London: Academic Press.

Spero, Aryeh. 1988. “'Conspicuous Consumption’ at Jewish Functions.” Judaism 37:103-10.

Spiro, Melford. 1961. "Social Systems, Personality, and Functional Analysis.” Pp. 93-128 in Studying Personality Cross-Culturally, edited by Bert Kaplan. New York: Harper and Row.

Stone, Lawrence. 1965. The Crisis of the Aristocracy 1558-1641. Oxford: Clarendon.

Sztompka, Piotr. 1974. System and Function: Toward a Theory of Society. New York: Academic Press.

Veblen, Thorstein. [1925]1970. The Theory of the Leisure Class: An Economic Study of Institutions. London: Unwin.

Weatherill, Lorna. 1988. Consumer Behaviour and Material Culture in Britain 1660-1760. London: Routledge. Weber, Max. 1964. The Theory of Social and Economic Organizations. New York: Free Press. 